\title{
VIOLENCIA ENTRE TORCIDAS ORGANIZADAS DE FUTEBOL
}

\author{
Carlos Alberto Máximo Pimenta \\ Professor de Sociologia na Universidade de Taubaté. Autor do livro Torcidas Organizadas de Futebol: \\ violência e auto-afirmação, aspectos da construção das novas relações sociais.
}

\begin{abstract}
Resumo: O presente artigo busca compreender o fenômeno da violência entre "torcidas organizadas", a partir das justificativas de explicação dos atos de violências utilizadas pelas "autoridades públicas” e torcedores. Mostra, em síntese, que a violência produzida pelos grupos de torcedores é parte da dimensão cotidiana dos grandes centros urbanos na sociedade brasileira contemporânea, conseqüência do esvaziamento político-cultural-coletivo dos novos sujeitos sociais.

Palavras-chave: futebol no Brasil; violência; torcidas organizadas.
\end{abstract}

$\mathrm{O}$ presente artigo tem a pretensão de explicitar que as práticas de violência produzidas pelas torcidas organizadas inflexionam-se e (re)dimensionam-se na base dos "jogos de relações" travados no cotidiano da sociedade brasileira contemporânea.

A reflexão proposta segue caráter essencialmente prospectivo e indagatório, cuja análise temática circunscreve-se em pesquisas empíricas qualitativas/críticas desenvolvidas junto às torcidas "Gaviões da Fiel", "Independente" e "Mancha Verde", sediadas na cidade de São Paulo, e sobre a violência implicada no processo de profissionalização da estrutura administrativa do futebol brasileiro, síntese das projeções políticas e econômicas de nosso Estado.

O recorte dessa reflexão se faz necessário, pois pretende-se buscar uma melhor compreensão de nosso tempo social, rompendo com visões reduzidas, conservadoras ou meramente estatísticas sobre o tema violência, bem como indicar apontamentos às modificações sentidas no cotidiano dos grandes centros urbanos brasileiros que (re)ordenam o comportamento dos grupos de jovens, em face das transformações políticas, econômicas e socioculturais em curso.

Por outro lado, mesmo com "toda" perspectiva de (re)visitar posturas mais ampliadas, sabe-se que não é muito tranqüilo iniciar discussão sobre violência, sob qualquer ótica. ${ }^{1}$ Trata-se de um tema ainda bastante penoso e pesado, do ponto de vista do objeto-sujeito, bem como do método determinista e/ou não-determinista. Contudo, em que pese a intranqüilidade exposta, caminhar é preciso e ir a fundo na questão significa atentar para as particularidades de cada violência e de como cada grupo faz uso dela ou nela está inserido. Não é tarefa (e nem abordagem) fácil!

Pois bem, é na tentativa de compreender nosso tempo social e na perspectiva de romper com visões reduzidas que são tomados como referência de observação os discursos de "autoridades" (desportivas, públicas, etc.) e de torcedores filiados para refutar atitudes e estratégias explicativas de violência, com ênfase no fortalecimento dos mecanismos de "segurança", direcionando ações do poder público ao "disciplinamento" e à "manutenção da ordem social vigente".

A violência vem ganhando parte significativa na agenda social, em especial nos veículos de comunicação de massa, parecendo assumir o epicentro das preocupações do poder público e do homem contemporâneo. No entanto, merece ser observada por outros ângulos cada vez menos policialescos ou midiáticos, para evitar que seja utilizada, apenas, como cenário de "espetáculo" e "banalização" humana.

A partir da visão dos "torcedores" (muitas vezes denominados vândalos ${ }^{2}$ em trabalhos científicos) e das "autoridades" envolvidas com o evento esportivo, busca-se relacionar a violência produzida entre as "torcidas orga- 
nizadas" com os "jogos" de relações sociais travados no espaço urbano. Pelos olhos desses envolvidos é que se encaminhará a fundamentação das questões levantadas.

A observação privilegiará os discursos coletados em pesquisa de campo ou em dados obtidos na imprensa escrita e televisiva, dos anos 80 em diante, tendo como ponto de partida:

- aumento da violência entre "torcidas organizadas";

- a intolerância com a violência, após o dia 20 de agosto de 1995, no acontecimento denominado de "Batalha Campal do Pacaembu";

- a incompatibilidade da violência com os rumos da profissionalização administrativa do futebol brasileiro.

\section{O FENÔMENO: "TORCIDAS ORGANIZADAS"}

A violência ao redor do futebol não é acontecimento novo e há exemplos na história do futebol brasileiro ${ }^{4} \mathrm{e}$ mundial (Murphy, Williams e Dunning, 1994:39-70) de atos de extrema violência entre torcedores. O que é inédito é o movimento social de jovens em torno de uma organização que difunde novas dimensões culturais e simbólicas no cotidiano urbano, amoldando o comportamento dos inscritos. Diante desse contexto, duas questões ficam registradas: quem são esses "torcedores"? Quais os motivos desse aumento considerável de violência?

Dos anos 80 para cá, sabe-se que, no Brasil, o comportamento do torcedor nas arquibancadas dos estádios de futebol modificou-se consideravelmente. Isso se deu pelo surgimento de configurações organizativas com característica burocrática/militar, ${ }^{5}$ fenômeno essencialmente urbano $^{6}$ que cria uma nova categoria de torcedor, ou seja, o chamado "torcedor organizado".

Fica uma indagação: em quais circunstâncias socioculturais, políticas e econômicas nasce essa "nova categoria de torcedor"? A questão perpassa todo texto e remete à análise da constituição do tecido social das grandes cidades.

As primeiras "torcidas organizadas" datam do fim da década de 60 e do começo dos anos 70. ${ }^{7}$ Nesse período, o Brasil caminhava em passos largos na busca do desenvolvimento econômico e a cidade de São Paulo avançava no processo de aceleração urbana, porém, notoriamente desarticulado e descompromissado com as bases sociais. ${ }^{8}$

A violência entre "torcidas organizadas" não está desarticulada dos aspectos político, econômico e sociocultural vivenciados nas relações individuais e grupais na socieda- de brasileira contemporânea. Conseqüentemente, o estilo de vida dos jovens, aqui denominados de novos sujeitos sociais, ${ }^{9}$ não pode ser dissociado dos desdobramentos causados por esses traçados político-econômicos legitimados no "jogo" social. Na década de 70, o poder de mando do complexo industrial interferiu nas macroorganizações político-econômicas, provocando grandes instabilidades nas microorganizações sociais emergentes.

Em outras palavras, o conflito entre os poderes econômico e social marcou a construção do espaço urbano das grandes cidades, prevalecendo o interesse do capital e, de alguma forma, esse processo interferiu, inclusive, na identidade social dos jovens que se expressam através da negação do outro (enquanto ser social), da disputa e da violência prazeirosa entre os grupos rivais.

Ademais, um apontamento possível desses desdobramentos é o esvaziamento da noção do coletivo na formação dos jovens, fator indispensável na compreensão dos novos sujeitos. $\mathrm{O}$ aumento dos atos de violência praticados pelo movimento de "torcidas organizadas" tem decorrência no surgimento desses "sujeitos". Estes são, predominantemente, jovens individualizados, do ponto de vista da formação de uma consciência social e coletiva. ${ }^{10}$ O diálogo grafado viabiliza melhor o entendimento da argumentação exposta:

"Repórter: - O que você acha dessa violência?

Torcedor: - (...) a gente tem um cachorro que vai e te morde e você vai ficar parado?"11

Os atos de violência perdem a percepção da existência do outro, enquanto pessoa do mesmo grupo social ou mesmo humana:

"Repórter: - Você chegou a bater em alguém?

Torcedor: - Não sei...

Repórter: - Você se defendeu pelo menos?

Torcedor: - Defendi...

Repórter: - O que você acha disso, você gosta?

Torcedor: - Gosto ... é só para chegar em casa e ter o prazer de tirar um barato com os meus amigos.

Repórter: - Não importa que alguém morra nisso?

Torcedor: - Não sendo amigo meu, tudo bem?" 12

Armando Nogueira, no programa "Apito Final", da TV Bandeirantes, no dia 20 de agosto de 1995, após o acontecimento no Pacaembu, percebeu que “(...) É com um constrangimento inimaginável. Eu estava vendo estas cenas aqui e não é o caso da gente fazer uma pergunta mais profunda, porque a paisagem humana que eu vi em campo era predo- 
minantemente de adolescentes, predominantemente de garotos e aí eu pergunto: como nos desculpar de tudo isso? O que o Brasil tem feito pela sua infância? O que o Brasil tem feito pela sua adolescência? (...) eu não tenho a menor dúvida que nós não podemos nos considerar inocentes."

\section{VISÃO DAS “AUTORIDADES ESPORTIVAS”}

A violência, via de regra, é o elemento aglutinador e constitutivo dos agrupamentos de torcedores. Nota-se que, no entendimento dessa modalidade de violência, aos olhos tanto dos "torcedores" quanto das "autoridades esportivas" os argumentos explicativos permanecem no eixo do econômico e da classe social, como determinantes.

Após o fatídico dia 20/08/1995, diversos discursos ${ }^{13}$ sucederam na imprensa e, por esse episódio, possibilitouse a revelação do entendimento das autoridades esportivas sobre os fatores geracionais de atos de violência entre "torcedores”. O repórter Flávio Prado entende que: “(...) Esses jogos de graça, envolvendo grandes equipes, são ótimos pretextos para que esses marginais compareçam."

Já o jornalista esportivo Juca Kfouri ${ }^{14}$ expressou: “(...) uma das soluções que eu vejo imediata é proibir, terminantemente, o futebol com portões abertos; futebol de massa nem pensar, porque é a senha para bandidos tomarem conta do estádio. Cobrar o ingresso e cobrar caro, cada vez mais caro, com cadeiras em todos os setores do estádio. Tornar o futebol um esporte para a elite, vão lá 40 mil abençoados por Deus, da alta classe média desse país (...). Evidentemente que não são os pobres os culpados pela violência. Os culpados pela violência a gente conhece desde a distribuição de renda neste país, mas que infelizmente, 90\% desses vândalos são do 'lumpesinato', são; são explorados, são; são um bando de desocupados, são (...) ou são explorados dessa gente, em regra os presidentes de 'torcidas organizadas' (...)."

O Promotor Público, Fernando Capez (1996:49), designado para mover ações públicas contra a legalidade das "torcidas organizadas", salientou que "(...) o recrudescimento dos problemas sociais e econômicos, o considerável aumento da distância entre os segmentos sociais, o alastramento generalizado da miséria, a falta de emprego e de acesso a um sistema de educação e saúde minimamente adequados, entre tantos outros problemas, acabaram criando perigosos focos de tensão social".

As sucessivas declarações caminharam no sentido de explicar a violência pelos mesmos condutores, ou seja, fatores econômicos e de classe social. A solução, por essa via, traduz-se no cerceamento do acesso dos torcedores aos estádios através da ação policial ou da majoração dos ingressos dos jogos. Portanto, o que se quer dizer é que tais discursos simplificados reforçam na ótica da opinião pública e das instituições repressivas que a violência tem corpo e rosto. Edson Arantes do Nascimento, o Pelé, ${ }^{15}$ argumentou que “(...) é muito triste. Eu que na época do milésimo gol pedi escola para as crianças, hoje peço cadeia para esses meninos".

Em outras palavras, essa linha de pensamento nos remete, apenas, a revermos as injustiças e as desigualdades, à inércia do Estado e à desestruturação da ordem legal, sem ao certo colocarmos em pauta o modelo de sociedade e suas trajetórias ideológicas no campo do "jogo" político-cultural.

\section{OS “ORGANIZADOS” E SUAS VISÕES}

Na intenção de compreender o fenômeno, é importante registrar que foi nos anos de 1992 e 1994 que ocorreu a maior parte dos envolvimentos, noticiados, entre "torcidas", resultando na morte de 12 pessoas, sendo quatro delas em 1992 e oito em 1994. Nesse período, os confrontos passaram a ser constantes e os instrumentos utilizados para defesa e/ou ataque tinham o poder de ocasionar lesões de natureza grave. Os "torcedores" começam a fazer uso de "bombas" e "armas de fogo", instrumentos, até então, pouco utilizados nos embates entre "torcidas". ${ }^{16}$

O fato de constatar-se que antes dos anos 90 não havia notícias de inúmeras mortes não significa que os confrontos inexistiam. Segundo Paulo Serdan, ${ }^{17}$ "as brigas eram na mão e não havia armas" (sic).

Em 1991, a "Mancha Verde" tinha 4.000 filiados, a "Independente", 7.000 e os "Gaviões da Fiel", 12.000. Até outubro de 1995, período em que passaram a ocorrer, por parte da Justiça Pública paulistana, cerceamentos das atividades desenvolvidas pelas "organizadas", estas "torcidas" tinham em seus quadros o registro de 18.000, 28.000 e 46.000 filiados, respectivamente. ${ }^{18}$

O afluxo de jovens às "torcidas", no entender de Jamelão, ${ }^{19}$ ex-presidente dos "Gaviões da Fiel", se deu porque "o monstro 'Gaviões' tem crescido muito desde 1990 e há uma grande procura por parte dos garotos de $13,14,15$ e até 18 anos. (...) essa procura é boa, aqui nós temos um conselho, nós temos um ideal e eu acho que nessas 'torcidas' está faltando um pouco disso (...)".

As novas filiações eram, basicamente, realizadas por jovens entre 12 e 18 anos de idade, atraídos pela 
vestimenta, força e coesão do grupo, relações verticalizadas, estilo de vida, prazer da violência, enfim, pelos aspectos estético-lúdico-simbólicos disponibilizados à massa jovem, intimamente ligados ao modelo de sociedade de consumo instaurado no Brasil.

A "Mancha Verde", por exemplo, fundada em 11 de janeiro de 1983, desde a escolha do nome até as atitudes praticadas nas arquibancadas e nas ruas da cidade, demonstrou ser uma "torcida" forte e preparada para enfrentar suas rivais: "escolhemos o nome 'Mancha Verde'com base no personagem 'Mancha Negra' do Walt Disney, que é uma figura meio bandida, meio tenebrosa. A gente precisava de uma figura ideal e de pessoas que estivessem a fim de mudar a história. Na época, a gente tinha uns 13/ 14 anos de idade e já havíamos sofrido muito com as outras 'torcidas', então, a gente começou com muita vontade, muita garra e na base da violência. A gente deve ter exagerado um pouco, porém, foi um mal necessário. A gente conseguiu o nosso espaço e adquirimos o respeito das demais 'torcidas'."

A violência, verbal e física, traduziu-se em um dos principais códigos e símbolos sociais de agrupamento de jovens em torno das "torcidas organizadas". À medida que os números estatísticos e os atos de agressividade aumentavam, proporcionalmente, cresciam a procura e a filiação ao movimento.

Como se explica, a partir dos próprios "torcedores", atos de extrema violência praticados entre "torcidas"? No entendimento dos dirigentes, o assustador aumento da violência, além dos argumentos utilizados pelas "autoridades esportivas", tem dois fatores preponderantes: a influência da mídia e os ingredientes do próprio "jogo". Para Paulo Serdan, “(...) a imprensa cria fatos que não existiu, mas a gente já está acostumado com isso (...). O lance é que o jornal tem que vender. (...) se as 'torcidas organizadas' cresceram muito, a imprensa ajudou muito também, porque essa molecada de hoje em dia, de 13, 14, 15 anos, não tem um ideal, nem um ideal político, nada" (sic).

Jamelão, ex-presidente dos "Gaviões da Fiel", acredita que "(...) a imprensa tem que chegar junto com a gente (...), porque todo aquele que for associado que está na faixa de 15 a 17 anos, vendo uma matéria no jornal: 'são-paulino toca bomba no corintiano', isso automaticamente fica na memória dele no próximo jogo, ele vai fazer bomba para atacar o são-paulino. (...) A imprensa ao invés de colaborar e querer saber quais os pontos para ter uma solução, eles preferem vender a imagem, vender o jornal (...)”.
$\mathrm{O}$ argumento mais recorrente utilizado por representantes de "torcidas" é que atos de violência podem ser gerados em face de inúmeros fatores intimamente ligados às teias de relações desenvolvidas no evento esportivo, abrangendo desde a estrutura dos estádios até a ação da polícia. Paulo Serdan sintetizou a justificativa: “(...) um detalhe do juiz, um detalhe do bandeirinha, um detalhe do policiamento. É uma série de detalhezinhos que vai insulflar a 'torcida' e vai criar um clima de guerra. Você chega num estádio e não tem água para beber, não tem banheiro para ir (...), um guarda que é um pouco violento (...), um bandeirinha que vira para trás e tira um barato com a cara da 'torcida' ou o próprio diretor de clube que o seu time faz gol, ele vira para a 'torcida' e tira um barato, então é uma série de detalhes que faz você sair do sério (...)".

O "torcedor", no modelo "organizado", não é mais um mero espectador do "jogo". No grupo ele é parte do espetáculo, ele é o espetáculo. No grupo ele expressa sua masculinidade, seus sentimentos de solidariedade, de companheirismo e de pertencimento em um grupo que o acolhe. Paulo Serdan entende que o fascínio se dá, pois “(...) essa juventude de hoje em dia não tem alguma coisa para se espelhar e se inspirar. (...) eles não têm no que se apoiar. (...) Qual o único segmento hoje em dia que expõe as suas vontades e os seus desejos, mesmo que seja em relação ao futebol? É a 'torcida organizada'".

\section{CONCLUSÃO}

A violência entre "torcidas organizadas" (acrescentase aqui o comportamento de inúmeros grupos de jovens) passou a ser uma preocupação social, uma vez que assumiu característica de acontecimento banal, débil e vazio. Na mesma proporção, passou a ser, também, um incômodo aos interesses em torno do evento esportivo.

As explicações que sucederam, restritas à observação dos discursos das "autoridades esportivas" e dos "torcedores", têm ressonância nas seguintes justificativas:

- má distribuição de renda;

- exploração dos dirigentes esportivos e dos líderes das "torcidas";

- efeitos da criminalidade;

- ausência de expectativa de futuro aos jovens;

- ausência do Estado, enquanto mentor de políticas públicas de formação social;

- efeitos da pobreza; 
- afrouxamento da ordem legal e das posturas repressivas das instituições de segurança e justiça;

- falta de emprego;

- miséria generalizada;

- familiarização com a violência;

- falta de infra-estrutura nos estádios de futebol;

- má arbitragem;

- gozações de adversários;

- derrota de uma partida de futebol.

Enfim, há um universo de argumentos e todos não são desprezáveis do ponto de vista da análise empírica. No entanto, os argumentos utilizados pelos "torcedores" e "autoridades esportivas" são insuficientes para aflorar aprofundamentos ao entendimento dessa modalidade de violência.

As atitudes e as estratégias explicativas da violência (seja qual for sua natureza) com ênfase apenas no fortalecimento dos mecanismos de "segurança", no direcionamento das ações do poder público ao "disciplinamento" e à "manutenção da ordem social vigente" devem ser, veementemente, refutadas para evitar injustiças e erros, historicamente repetidos. Primeiro, porque quem produz a violência, no visor imaginário do senso comum, é só a pessoa de baixo poder aquisitivo, pobre, negro ou mestiço. Segundo, porque a ordem dominante não reconhece que a violência pode constituir outras formas de relações sociais, reproduzindo representações, códigos e estilos de vida próprios..$^{20}$ Por fim, porque o discurso dominante não reconhece que o indivíduo faz parte de um sistema social de padronização subjetiva e que recebe informações de diversas ordens, reagindo aos estímulos com afetos, angústias, frustrações, excitações, prazer, etc.

Não cabe atribuir as causas da violência, exclusivamente, às questões de classe social ou fatores estritamente econômicos. Na composição de uma "torcida" participam pessoas que respondem a processos criminais, viciados, estudantes, trabalhadores das mais diversas profissões, pais de família, mulheres, jovens. Existe uma pluralidade de "agentes" que assumem diversos papéis nos "jogos" de relações sociais. Paulo Serdan, ao descrever o perfil dos filiados da "organizada" que faz parte, salientou que a "torcida" é “(...) um grupo diversificado. Aqui temos pessoas de todas as classes. (...), temos pessoas aqui que participam de partidos políticos (...), ricos, pobres, negros, amarelos, viciados (...). A gente forma uma grande família".

Pode-se dizer que os sócios das "organizadas" são pessoas normais que gostam de futebol, do "barato" promo- vido pelas "torcidas" e vão aos estádios de futebol pela diversão, pela viagem, pela bebida, pela excitação do "jogo" e, até, pelo prazer de atos de violência. ${ }^{21}$

Não cabe, em igual proporção, pensar a violência entre "torcidas", no caso do Brasil, negando os efeitos do esvaziamento político do sujeito social, em especial dos agrupamentos de jovens, instaurado no processo de construção de uma "sociedade atomizada" (Scherer-Warren, 1993:112-113) e impulsionado pelos traçados ideológicos dos governos militares.

Para se ter uma idéia, extra-oficialmente, ${ }^{22}$ as vítimas fatais nos enfrentamentos entre torcedores de futebol chegam a 29 casos, sendo que a maioria pertence à faixa etária de 10 a 22 anos, totalizando 20 casos. Desses, 15 casos ocorreram de 1992 em diante. O comando do $2^{2}$ BPChq ${ }^{23}$ da cidade de São Paulo, constatou que os agressores são “(...) menores de 18 anos. A média de idade é 16 anos dos elementos que praticam atos violentos. Isso não significa dizer que a gente não detenha indivíduos maior de idade. Isso ocorre, mas existe uma grande maioria de menores que praticam atos de violência".

$\mathrm{Na}$ articulação vem-se reforçando a idéia de que a violência não é disjunta da realidade social e que é parte da dimensão real do cotidiano dos espaços urbanos das grandes cidades brasileiras e, consecutivamente, dos grupos de jovens. Portanto, a mola propulsora dessas dimensões sociais, combinadas com uma infinidade de fatores históricos, econômicos e socioculturais, ganha efeito pela produção do esvaziamento político do sujeito social.

Nesse sentido, observa-se que os atos de violência transformam-se em um plus nesses acontecimentos e circulam além das questões de classe social ou de efeitos do econômico. Ou seja, no novo sujeito social, no caso o "torcedor organizado", o prazer e a excitação gerados pela prática de atos de violência podem ser elementos importantes na interpretação do comportamento juvenil, uma vez esvaziado de sua capacidade de ser sujeito coletivo.

Três aspectos se convergem para justificar e explicar a violência entre "torcidas": a juventude, cada vez mais esvaziada de consciência social e coletiva; o modelo de sociedade de consumo instaurado no Brasil, que valoriza a individualidade, o banal e o vazio; e o prazer e a excitação gerados pela violência ou pelos confrontos agressivos.

O que se arrisca, por derradeiro, dizer é que a violência caracterizou-se como parte intensa nas dimensões do cotidiano urbano contemporâneo, em especial dos grandes centros, sendo que uma pista importante, diante da intole- 
rância da "comunidade" esportiva e das "autoridades públicas" ao movimento de "torcidas organizadas", cinge-se na indicação de que a repressão (policial, legal, etc.) contribui para manter uma "suposta ordem", porém, contribui, também, no deslocamento dessa massa jovem para outros movimentos de busca de prazer e de excitação.

\section{NOTAS}

E-mail do autor: cpimenta@iconet.com.br

1. A academia brasileira, nas últimas décadas, tem buscado respostas às múltiplas facetas da violência, reconhecendo que o fenômeno transformou-se, sem sombra de dúvidas, em uma das maiores preocupações no imaginário urbano. Ver, nesse sentido, os trabalhos de Pinheiro (1982), Da Matta (1982), Pires (1985), Morais (1985), Odália (1986), Benevides (1982), Costa (1993), entre outros. Contudo, a temática da violência ainda é um assunto difícil e arenoso da promoção de intervenções acadêmicas.

2. O termo vândalo ou vandalismo é muito utilizado por investigadores europeus para distinguir o torcedor comum do violento, no caso europeu: Hooligan. Ver os trabalhos de Duran Gonzalez (1996a e 1996b), Buford (1992), entre outros. A proposta é evitar a utilização desse termo para, conseqüentemente, evitar a rotulação policialesca ou midiática empregada aos acontecimentos de violência entre torcedores organizados no Brasil.

3. Após o acontecimento do Pacaembu, as atividades das "torcidas organizadas" foram proibidas, por ordem judicial e, conseqüentemente, houve a extinção dessas entidades. O fato ocorreu somente no Estado de São Paulo. Contudo, não significa que elas não marquem presença nos estádios de futebol e deixaram de fazer suas reivindicações junto aos clubes. Recentemente, os "Gaviões da Fiel" invadiram a sede do S. C. Corinthians Paulista e agrediram os jogadores de futebol, alegando ausência de ânimo e desempenho dos mesmos nas partidas (Diário Popular, 28/06/2000:5).

4. Atos de violência acompanham o comportamento dos torcedores desde o início dos jogos de competição. Rodrigues Filho (1964:20-24) em O negro no futebol brasileiro, menciona que "quando o Bangu vencia, muito bem, não havia nada, o trem podia voltar sem vidraças partidas. Quando o Bangu perdia, porém, a coisa mudava de figura; os jogadores da cidade trancavam-se no barracão, o vestiário da época, não queriam sair só com a polícia, os torcedores corriam para esconder-se no trem, deitando-se nos bancos compridos de madeira, enquanto as pedras fuzilavam, partindo vidros, quebrando cabeças. Vinha a polícia, os jogadores saíam do barracão, bem guardados, os diretores do Bangu atrás deles, muito amáveis, pedindo desculpas. Numa confusão dessas era natural que ninguém se lembrasse da taça oferecida ao vencedor. Daí a expressão que pegou: 'ganha, mas não leva'. O clube da cidade podia ganhar o jogo. A taça, porém, ficava lá em cima".

5. Por "burocrática-militar" entende-se grupos de torcedores que formam, ao seu redor, estrutura organizativa com base em estatutos, quadro associativo, departamento administrativo e de vendas, sede para ponto de encontro, reuniões, interação social e que estão preparados, se necessário, para o confronto físico e verbal contra os grupos rivais. Os "Gaviões da Fiel" modificaram o estilo das torcidas existentes institucionalizando formas de organização, administração e "estratégias" e "táticas" de defesa em confrontos com os "inimigos", semelhantes às práticas produzidas nos governos militares, pelo menos quanto à utilização simbólica da linguagem militar (linha e pelotão de frente, combate, etc.). Ver Pimenta (1997:64-82). A categoria "burocrática-militar", apropriada no texto, foi denominada pelo professor Maurício Muhad, pesquisador/fundador do Núcleo Permanente de Estudos de Sociologia do Futebol, do Departamento de Ciências Sociais, do Instituto de Filosofia e Ciências Humanas da UERJ.

6. Para ampliar o entendimento da afirmação de ser as "torcidas organizadas" um fenômeno urbano, ver Toledo (1996a:124-155).

7. Consideram-se os "Gaviões da Fiel" a "torcida organizada" mais antiga do Brasil. Os "Gaviões" representam a primeira torcida a ter uma estrutura organizativa regida por regras estatutárias e com característica burocrática/militar, compondo-se de presidente e vice, conselheiros e diretores, eleitos periodicamente, formando instituição privada sem fins lucrativos e seus sócios são tratados de forma "impessoal". A "torcida" foi fundada em 01/07/1969, com o ob- jetivo de fiscalizar e apontar todos os erros praticados pelos dirigentes do S. C. Corinthians Paulista, auto-intitulando-se "os representantes da nação corintiana" junto à Instituição-Clube. A identificação desses grupos é percebida pela vestimenta, pela virilidade e masculinidade, pelos cânticos de guerra, pelas transgressões das regras legais, pelas coreografias, pelo sentimento de pertencimento ao grupo e pela necessidade de auto-afirmação. As "torcidas organizadas" opõemse aos modelos considerados, demasiadamente, pacíficos adotados pelos "charangas", bandas musicais que a partir dos anos 40 davam nas arquibancadas um tom carnavalesco de torcer pelo seu clube. Para aprofundar sobre o tema, ver Toledo (1996a:21-38) e Pimenta (1997:64-93).

8. Nesse sentido, o trabalho de Kowarick (2000) traz referências importantes sobre construção dos espaços urbanos, nos grandes centros brasileiros.

9. Entende-se por "novos sujeitos" os indivíduos, na sua maioria jovens, que interagindo nos "jogos de relações sociais" sofrem(ram) esvaziamento de suas identidades e personalidades coletivas ou alguma forma de exclusão pela "ordem dominante" e que buscam, através de atos denunciatórios ou agressivos, rosto social, resistência cultural e pertencimento a grupos coesos que lhes dêem a possibilidade de vida social (Pimenta, 1996:17-26).

10. Sobre os fatores que influenciam o esvaziamento da consciência social e coletiva do sujeito, ver Chauí (1986), Zermeño (1990:54-62) e Scherer-Warren (1993:112-113).

11. Extraído de reportagem produzida pela TV Bandeirantes, em 20/08/1995, após a Batalha Campal do Pacaembu, com torcedor da "Mancha Verde", suposto autor da morte do "Independente" Márcio Gasperin da Silva.

12. Fala de Adalberto Benedito dos Santos, torcedor da "Mancha Verde", apontado como autor da morte do "Independente" Márcio Gasperin da Silva. TV Bandeirantes, 20/08/1995.

13. Os dados foram extraídos dos programas "Cartão Verde" (TV Cultura), "Show do Esporte" (TV Bandeirantes), produzidos no dia 20/08/1995, "Jornal do SBT", "Globo Esporte", produzidos no dia 21/08/1995, e no Seminário A Violência no Esporte, promovido pela Secretaria da Justiça e da Defesa da Cidadania do Estado de São Paulo, uma semana após o acontecimento do Pacaembu, realizado na Faculdade de Direito da USP, sob a coordenação de Júlio Lerner.

14. O jornalista esportivo Juca Kfouri, no Seminário A Violência no Esporte (1996:61-64), reproduziu sua visão infeliz.

15. Folha de S.Paulo, 21/08/1995. Pelé retificou seu pensamento, posteriormente, dizendo que "(...) agora eu pedia cadeia para quem um dia pedi atenção, muitos entenderam que eu estava propondo a prisão de menores de idade. Certamente não me expressei bem, então. O que quis dizer, e repito, foi no sentido de que os abandonados de novembro de 1969 tinham virado os delinqüentes de agosto de 1995. Eles e seus filhos - e é claro que a sociedade precisa ter defesas contra a violência" (Pimenta, 1996:17).

16. Todos os dados contidos nesse parágrafo foram extraídos da sistematização de 614 textos jornalísticos da imprensa escrita paulista, de janeiro de 1980 a dezembro de 1999.

17. No presente texto, todas as falas de Paulo Serdan são datadas de julho de 1995, na época presidente da "Mancha Verde".

18. Dados obtidos junto às mencionadas "torcidas", em abril de 1995.

19. Entrevista realizada em abril de 1995. Todas as "falas" de Jamelão, contidas nesse texto, referem-se à entrevista supra.

20. Nesse sentido, ver Ortiz (1983), Elias e Dunning (1992), Diórgenes (1998), Costa (1993), entre outros.

21. Sobre a questão da excitação e do prazer pela prática de atos que fogem aos padrões de controle estabelecidos pelas sociedades capitalistas, ver Elias (1992b).

22. Os dados foram coletados na imprensa escrita de São Paulo, de janeiro de 1980 a dezembro de 1999 .

23. Dados coletados junto ao comando do 2o BPChq, da Cidade de São Paulo.

\section{REFERÊNCIAS BIBLIOGRÁFICAS}

BENEVIDES, M.V. "Linchamentos: violência e 'justiça' popular”. In: VVAA. Violência brasileira. São Paulo, Brasiliense, 1982.

BUFORD, B. Entre os vândalos: a multidão e a sedução da violência (Tradução Júlio Fischer). São Paulo, Companhia das Letras, 1992. 
CAPEZ, F. "Violência no futebol". In: LERNER, J. (ed.). A violência no esporte. São Paulo, Secretaria da Justiça e da Defesa da Cidadania/Imesp, 1996, p.49-52.

CHAUÍ, M. Conformismo e resistência: aspectos da cultura popular no Brasil. São Paulo, Brasiliense, 1986.

COSTA, M.R. da. Os carecas do subúrbio: caminhos de um nomadismo moderno. Petrópolis, Vozes, 1993.

COSTA, M.R. da et alii (orgs.). Futebol, espetáculo do século. São Paulo, Musa, 1999.

DA MATTA, R. “As raízes da violência no Brasil: reflexões de um antropólogo social”. In: VVAA. Op. cit., 1982.

DIÓRGENES, G. Cartografias da cultura e da violência: gangues, galeras e o movimento hip hop. São Paulo, Annablume/Secretaria da Cultura e Desporto de Fortaleza, 1998.

DURAN GONZÁLEZ, J. El vandalismo en el fútbol. Una reflexión sobre la violencia en la sociedad moderna. Madrid, Gymnos, 1996a.

. "El vandalismo en el fútbol". Valores sociales y deporte: fair play versus violencia. Madrid, Consejo Superior de Deportes, n.9, 1996b, p.935.

ELIAS, N. A busca da excitação (Tradução de Maria Manuela Almeida e Silva). Lisboa, Difel, 1992.

ELIAS, N. e DUNNING, E. Deporte y ocio en el proceso de la civilización. Madrid, Fondo de Cultura Económica, 1992.

KFOURI, J. "Sonhar de olhos abertos". In: LERNER, J. (ed.). Op. cit., 1996, p.61-64.

KOWARICK, L. Escritos urbanos. São Paulo, Editora 34, 2000.

LERNER, J. (ed.). A violência no esporte. São Paulo, Secretaria da Justiça e da Defesa da Cidadania, Imesp, 1996.

MORAIS, R. de. O que é violência urbana? São Paulo, Brasiliense, 1985.

MURPHY, P.; WILLIAMS, J. e DUNNING, E. O futebol no banco dos réus: violência dos espectadores num desporto em mudança (Tradução de Raul Sousa Machado). Oeiras/Portugal, Celta Editora, 1994.

NASCIMENTO, E.A. “O gol cidadão”. In: LERNER, J. (ed.). Op. cit., 1996, p.17-18.

ODÁliA, N. O que é violência? São Paulo, Brasiliense, 1986.
ORTIZ, R. (org.). "Gostos de classe e estilos de vida”. In: BOURDIEU (Coleção Grandes Cientistas Sociais). São Paulo, Ática, 1983.

PIMENTA, C.A.M. “A complexidade das relações societárias e os novos sujeitos: a violência como ponto de partida”. Revista Ciências Humanas. Taubaté, Unitau, v.2, n.1, 1996, p.17-26.

Torcidas organizadas de futebol: violência e auto-afirmação, aspectos da construção das novas relações sociais. Taubaté, Vogal, 1997.

. "As transformações na estrutura do futebol brasileiro: o fim das torcidas organizadas nos estádios de futebol". In: COSTA, M.R. da et alii. Op. cit., 1999, p.131-145.

. "Novos processos de formação de jogadores de futebol e o fenômeno das 'escolinhas': uma análise crítica do possível". In: ALABARCES, P. (org.). Peligro de gol. Estúdios sobre deporte y sociedad en América Latina. Buenos Aires, Clacso, 2000, p.75-97.

PINHEIRO, P.S. "Polícia e crise política: o caso das polícias militares". In: VVAA. Op. cit., 1982.

PIRES, C. A violência no Brasil. São Paulo, Moderna, 1985.

RODRIGUES FILHO, M. O negro no futebol brasileiro. Rio de Janeiro, Civilização brasileira, 1964.

SCHERER-WARREN, I. Redes de movimentos sociais. São Paulo, Edições Loyola, 1993.

SILVA, E.M. da. As 'torcidas organizadas de futebol': violência e espetáculo nos estádios. Dissertação de Mestrado. São Paulo, Departamento de Ciências Sociais da PUC/SP, 1996.

TOLEDO, L.H. de. "Transgressão e violência entre torcedores de futebol". Dossiê futebol. São Paulo, Universidade de São Paulo, n. 22, jun./jul./ago. 1994, p.92-101.

. Torcidas organizadas de futebol. Campinas, Autores Associados/ Anpocs, 1996a (Coleção Educação Física e Esportes).

. "A cidade das torcidas: representações do espaço urbano entre torcedores e torcidas de futebol na cidade de São Paulo". In: MAGNANI, J.G.C. e TORRES, L. de L. Na metrópole: textos de antropologia urbana. São Paulo, Edusp/Fapesp, 1996b, p.124-155.

ZERMEÑO, S. "El regreso del líder". Revista del Clasco. Buenos Aires, Clacso, n.56, abr. 1990, p.54-62. 